\title{
Improving the Methodology of Integrated Teaching of The Subject of Native (Uzbek) Language
}

\author{
Klarakhon Makhmutovna Mavlonova \\ $\mathrm{PhD}$ in the Pedagogical Sciences, Senior Lecturer of the Chair of Applied Linguistics and Linguodidactics, Tashkent State \\ University of Uzbek Language and Literature named after Alisher Navoi, Uzbekistan \\ *klara_mavlonova@mail.ru \\ ORCID iD: https://orcid.org/0000-0003-4954-9996
}

\begin{abstract}
Introduction: The article was written with the aim of improving the method of integrative study of the subject of the native language with literature through a literary text.

Materials and methods: When covering the topic, the following methods were used: comparative analysis, pedagogical observation, the study of advanced pedagogical experience, sociological methods questioning, conversation), pedagogical experiment, mathematical and statistical analysis.

Research results: In the 2015-2016 academic year, before the start of experimental classes in 9 grades, in which these lessons are intended, in order to find out the knowledge, skills and abilities of students in finding a literary text, artistic visual aids and types of poetic art, their name and explanation, test papers. After the lessons, on the basis of experimental materials, a mathematical calculation of the results of control works was carried out in order to compare the qualitative changes before and after the experiment. Discussion and conclusions: The increase in the number of literary texts in the textbooks "Native Language" for grades 5-9 has created the opportunity and the need to work on artistic visual aids and types of poetic art through these texts. The expediency of the implementation of external and bilateral integration of native language lessons with literature lessons through literary texts is substantiated, considering such basic approaches as communication, focus on speech activity, ingenuity, awareness and differentiation, such principles.
\end{abstract}

Keywords:

native Uzbek) language, literature, integration, literary text.

Acknowledgements: We express our gratitude to Niyozmetova Roza Khasanovna - Professor, Doctor of Pedagogical Sciencesю

Article Received: 18 October 2020, Revised: 3 November 2020, Accepted: 24 December 2020

\section{Introduction}

In the world in the context of globalization, attention is paid to improving the content of integrative teaching of disciplines, the UNESCO International Concept of Education defines the tasks of improving the quality of education, stimulating creative thinking and acquiring knowledge. In leading higher educational institutions of Great Britain, Germany, Korea, Switzerland, Hungary, Russia and China, interactive educational technologies have been introduced into the process of teaching language and literature, and the content of education has been improved on the basis of integrative principles.
The world explores the theoretical issues of using literary materials in the formation of linguistic and speech competencies in students, mastering language knowledge through literary texts, studying the linguistic features of a literary text in accordance with literary concepts in the lessons of the native language. Scientific research is being conducted in such priority areas as integrative teaching of academic subjects in the native language and literature, the study of the peculiarities of the language of a literary text based on literary concepts, the use of works of art to develop students 'creative thinking abilities, and increasing the effectiveness of education by developing students' creative thinking. 
In our republic, the continuity and consistency of teaching general education disciplines, including the native language and literature, has been ensured, the transition to 11-year secondary education has been carried out, the regulatory and legal framework for the content of education and upbringing has been improved, a solid material and technical base has been created. The definition of "further improvement and development of the lifelong education system" as a priority area in the field of education in the Strategy of Actions for the Further Development of the Republic of Uzbekistan has expanded the possibilities for a radical improvement in the quality of teaching in all levels of the education and upbringing system of the Uzbek language and literature, as well as training highly qualified personnel in this area, improvement based on the integration of disciplines of the content and teaching methods, integrated teaching of the native language with literature through the literary text, a special study of the possibilities of modern textbooks "Native Uzbek) language", the formation of speech competence and creative thinking of students at the level of modern requirements.

\section{Literature review}

The issues of teaching the native language and literature in the process of general secondary education, the development of creative intelligence and speech of students were studied by scientists Y. Abdullaev (1, 2), T. Ziyadova (24), A. Gulomov (10); the problems of studying the native language and literature in interconnection with each other were investigated by scientists A. Aliev (25), A. Zunnunov (25), K. Yadgarov (22), Qobilova Z., Aliyeva G. (17) investigated the linguodidactic foundations of studying the language of a literary text in academic lyceums.

Work on artistic text in Russian lessons, ways of developing students' speech by integrating their native Russian) language and literature on the basis of artistic materials have been studied by such scientists from the CIS countries as R. Doschinsky (7), A. Pronina (16), Y. Ganshina (9), E. Markina
(14), G Stukolkina (20), G. Mamon (13), A. Loichenko (12), A. Albetkova (4, 5, 6), N. Semenova (18), Tekuchev A.V (21).

Such scientists from far abroad as A. Anderson, L. Krakaur, G. Lazar, I. Butler investigated the effectiveness of the integration of language and literature at the stages of education; and the issue of language learning through literary texts in teaching was investigated by scientists P. Kennedy, P. Falfey.

\section{Materials and Methods}

When preparing experimental materials, considering the level of students' knowledge of linguistic phenomena used to ensure artistry, the main shortcomings and their causes, it is considered advisable to check on the basis of the following three parameters that characterize the degree of formation of knowledge, skills and abilities of students:

- the ability to read a literary text to identify a linguistic phenomenon that enhances its artistry, to find an artistic pictorial means or a type of poetic art, used with skill in creating artistic value;

- the ability to name an artistic means of expression or a type of poetic art;

- the ability to give an explanation to him.

It was believed that if students can find in an artistic text an artistic visual means or a type of poetic art, name and explain it, then they can further enrich their creative written work with these means; otherwise, in the writings of students who have not mastered these means, serious changes can occur only on the basis of intuitive awareness of them.

Experimental materials are prepared in the form of lesson development on the following topics:

- comparison and impersonation for grade 5; two topics related to the symbol each with 5 lessons); 
- tanosub poetic art), which is a form of poetry 7 lessons for 7-8 grades). The work provides the development of these lessons on the indicated topics.

Lessons scheduled for grades 5 and 7 were repeated in grades 8. At the same time, the goal was to organize, at the beginning of the next 2016-2017 academic year, final tests in 9 grades of schools, in which experimental lessons were held in order to find out how much knowledge, skills and abilities were preserved in the minds of students.

For the test, prose excerpts and semi-verses were used.

Research methods. When covering the topic of the dissertation, the following methods were used: comparative analysis, pedagogical observation, the study of advanced pedagogical experience, sociological methods questionnaire, conversation), pedagogical experiment, mathematical-statistical analysis.

\section{Methodology}

The aim of the research is to improve the methodology of integrative study of the subject of the native language with literature through a literary text.

\section{Research objectives:}

to analyze from the pedagogical and methodological points of view the problems of integration of the native language and literature through the literary text, the current state of the content of education associated with the means of artistic representation and types of poetic arts studied in literature lessons in grades 5-9;

improve the content, didactic components and methods of integrative teaching of academic subjects in the native language and literature;

to characterize the reading and artistic perception of a literary text by students in their native language lessons and develop scientifically based recommendations for teaching expressive reading;

to improve the methodology of teaching students in the lessons of their native language, to find, name, explain, analyze the means that provide artistry, and create a text in an artistic style.

The object of research is the process of teaching the subject of the native language by improving the methodology based on integration with the subject of literature through a literary text.

The subject of the research is the content, forms, means and methods of teaching the subject of the native language by improving the methodology based on integration with the subject of literature through a literary text.

The scientific novelty of the research is as follows:

- the content of teaching the native language and literature has been improved on the basis of bilateral interaction) and external enrichment of the content of teaching the native language with literary concepts) integration of linguistic concepts of artistic representation and types of poetic arts;

- the procedure for integrated teaching of the native language and literature was clarified on the basis of approaches of communication, focus on the formation of speech competence, ingenuity, conscious and differentiated approaches, principles of continuity and continuity;

- the method of teaching expressive reading of students in the lessons of their native language has been improved on the basis of paying attention to the figure and background, the priority of aesthetic impact and creative thinking in reading and artistic perception of a literary text;

- the methodology of teaching students in the lessons of their native language to find, name, explain, analyze the means that provide 
artistry, and create a text in an artistic style has been improved on the basis of Bloom's taxonomy categories knowledge, understanding, application, analysis, generalization, assessment).

The practical results of the study are as follows:

- developed and introduced into practice a sequence of studying the linguistic features of a literary text in the lessons of the native language in the amount of knowledge, skills and abilities that must be mastered in artistic visual means and types of poetic art, guidelines for expressive reading of a literary text based on its artistic perception, according to finding, naming, explaining analyzing) linguistic phenomena that ensure artistry;

- recommendations for making some changes in the content of education studied in the subject of literature have been developed and introduced into practice;

- $\quad$ the results of the study were used to create a new SES and training programs based on a competence-based approach.

The reliability of the research results is determined by the fact that the approaches and principles followed in the dissertation, the applied methods and theoretical information were taken from official sources, were based on the ideas of domestic and foreign scientists, on the experience of practicing teachers, the effectiveness of the analyzes and experimental work was substantiated by means of the mathematical-statistical method. , suggestions and recommendations were introduced into practice, the results obtained were confirmed by authorized competent) structures.

Scientific and practical significance of the research results.

The scientific significance of the research results is determined by the fact that it analyzes the integration of the native language with literature through literary texts, the existing state of the content of education related to artistic visual means and types of poetic art studied in literature lessons in grades 5-9, proposals for improving the content of teaching academic subjects native language and literature from the point of view of integrative teaching of artistic visual means and types of poetic art through literary texts, which in the improved methodology substantiates the content and methods of forming speech competence in students, developing their creative abilities, instilling in them mastery in word usage, are revealed peculiar features of artistic perception of literary texts in the lessons of the native language, which differ from the perception in literature lessons.

The practical significance of the research results is determined by the fact that the ideas put forward in the research, practical recommendations serve to improve the textbooks "Native language" and "Literature", improve the quality of integrative teaching of academic subjects, native language and literature, create textbooks and methodological aids on specialized subjects, teach these subjects at the university, use in refresher courses, as well as the use by teachers of their native language and literature in the process of conducting lessons.

\section{Results}

Theoretical and methodological foundations of teaching the subject of the native language based on integration with literature through a literary text.

The formation of a speech culture in students is part of the requirements for quality indicators determined in the subject "Native Uzbek) language" in the State Educational Standard: "the formation of speech and linguistic competencies in students aimed at developing the correct and consistent presentation of their thoughts, using the broad capabilities of the native language." These qualities of speech development are also enriched by teaching the native language on the basis of integration with literature through a literary text, i.e. the use of theoretical knowledge in the lessons of the native language, acquired by 
artistic means and types of poetic art, skills and abilities learned in literature lessons.

It should be noted that, based on sources on literary studies in teaching literature, it is advisable to call artistic means of expressiveness not as given in the textbooks "Literature", but dividing them into two groups: artistic graphic means for prose texts) and poetic arts for poetic works), based on this, use the term allegory tashbih) only when analyzing poetic samples, and when analyzing prosaic texts - the term comparison o'xshatish), to clarify the following two-fold explanation given in the textbook: "Artistic means of expression are also called poetic arts" ...

In native language lessons, integration with other academic subjects is carried out to varying degrees. According to B. Abdullayeva (3), according to the way of ensuring communication between academic subjects, there can be one-sided, two-sided, multilateral integration. With one-sided integration, one academic subject takes as an example from the other what is suitable for the purpose, in the second, unification, enrichment of each other's content through mutual influence is carried out. With one of the subjects for example, the Russian language, foreign languages, partly history), a one-sided integration occurs, and with the second, more clearly, only with the academic subject, literature, which is the art of words, arises two-sided integration. A positive experience is taken as an example for the content of teaching a native language, more of Russian language, less of foreign languages, history, but these academic subjects cannot give serious recommendations for changing the content of teaching this subject. When we talk about unilateral integration, we mean the above circumstances. It will be correct to consider that the integration of the lessons of the native language with the lessons of literature is both twoway and external integration. For the content of teaching the native language is enriched by work on artistic visual aids and types of poetic art external integration), appropriate proposals are made to change the sequence of studying theoretical concepts regarding the content of literary education.

When integrating with each other through the literary text of academic subjects, the native language and literature, along with several basic approaches, takes a special place in the communicative approach. "The main function of language is communication - to communicate something), while expressiveness complements communication: as an addition to the expressed thought, joy, anger, resentment, affection, etc. are added." The aesthetic impact of a literary text is formed with the help of emotionally expressive linguistic phenomena, artistic pictorial means and types of poetic art. This means that it is necessary to look at literary texts not only from the educational and educational side, but from the point of view of their aesthetic impact. This view acts as a factor prompting the teacher to integrate the two subjects.

Among the principles, the principle of reliance on the knowledge of students acquired in the lessons of their native language stands out. According to this, the linguistic features of a literary text are brought in accordance with the framework of knowledge presented in two academic subjects. For example, when speaking about words with a figurative meaning in the lessons of the native language, it will be correct to refer to the theoretical information about what is learned in literature lessons. After studying homonyms, students can be required to find in the literary text and explain the "tajnis".

An important aspect of the study is the definition of the concepts studied in literature lessons on artistic visual means and types of poetic art, and the methods of their study, the integration of the content of teaching the native language with the content of literary education. In the course of the research, these issues were resolved by determining, on the basis of analysis of the materials given in the textbooks "Book for reading" "O’qish kitobi") of 3-4 primary grades, theoretical 
information given in textbooks and textbooksreaders "Literature" for 5 -9-grades, questions and tasks for the works proposed in them. In the "Book for Reading" textbooks for primary grades, questions and tasks are given on the following means of expressiveness: in the 3rd grade, comparison o'xshatish), in the 4th grade, comparison and personification o'xshatish and jonlantirish), the term impersonation jonlantirish) is used. But in the 5th grade literature curriculum, concepts learned in primary school, such as comparison and impersonation, are not even reflected as material for review.

The dissertation analyzes the available theoretical information, questions and tasks for each work in the textbooks and textbooks-readers "Literature" for grades 5-9. The paper details these analyzes; shows cases of lack of integration with the topics studied in the lessons of the native language. Attention is drawn to the fact that the correspondence of the two academic subjects, first of all, has not been resolved in the content of education in the programs on the native Uzbek) language and literature.

In the textbook "Literature" for 5, a textbook-reader for 6 grades, in order to consolidate certain artistic visual aids or types of poetic art, such questions and tasks are used, from which one can take as an example for lessons in the native language, such as those requiring to remember the necessary term, to determine their function, evaluate their place in the description, say whether they have a symbolic meaning, find examples from the work. In high school, these works are associated with the artistic skill of poets and writers. However, due to the fact that in the textbooks-readers for these classes there are no specific classification information about artistic figurative means and types of poetic art, the same term is used for both prose texts and poetry, there are cases of going beyond the program. This circumstance negatively affects the knowledge of students.
The work examines such questions as whether there are in literary texts or there are no examples of artistic figurative means and types of poetic art, given as material for exercises and tasks for their analysis in the textbooks "Native Language" for grades 5-9, is there sufficient theoretical information about the artistic style.

It should be emphasized that after studying the linguistic features of a linguistic phenomenon, the teacher proceeds to clarify new aspects of the literary text - to the means that provide artistic value. Such a transition increases the interest of students, awakens in them a desire to get acquainted, for practical purposes, with the means that ensure artistry. In particular, this arises the need to study the secrets of creativity, the implementation of creative tasks.

It is appropriate here to quote the following statement of Abdulla Avloni, said about the lesson and education: "Although there is an insignificant difference between the lesson and education, they are both inseparable, just as the soul and body are connected." If work on linguistic knowledge is considered a lesson, then the improvement of speech culture is both training and education. From the statement of A. Avloni, it becomes clear that it is wrong to limit ourselves to studying only grammar itself in the lessons of the native language.

During the study, about 100 hours of lessons in the native language and literature were attended, a conversation was held with teachers, a questionnaire was drawn up, answers to them were received and analyzed.

Observations show that teachers in their native language lessons usually work on literary texts as part of the textbook assignments; sometimes, to reinforce a new topic, they force students to complete only the assignments given in the Native Language textbooks. At the same time, they draw the attention of students to only two educational functions of a literary text: finding and 
explaining a linguistic phenomenon being studied on a new topic; a definite educational problem. In many cases, teachers treat literary texts - the material of the exercise - as they relate to ordinary educational texts. For this reason, no task is given to determine the artistic visual means or the type of poetic art available in the literary text. Whereas, "... the era demands from textbooks on the native language to provide not only knowledge about the construction of the Uzbek language, but also mechanisms and methods of mastering the rich possibilities of the language in the full sense."

Observations have shown that the choice of a particular style for writing an essay by students in grades 5-9 depends on its topic. As it became known, even if they are not yet given information about the styles of speech, even if the types of styles have not been studied, as soon as such topics as: "What is Motherland?", "Mother is a great personality," "Spring is the bride of the season", "Emerald Spring", "My Future Dreams", students come to the idea that writing should be written in an exalted spirit. In the essays written by students about the Motherland, about the mother, about spring, about the future, one can feel inner feelings, excitement, a sense of pride and honor. These mental states, hidden in the depths of words, act as a powerful factor in prompting the artistic writing of an essay. Naturally, the process of covering the topic encourages the student to express their feelings with colorful, bombastic words, word forms and sentences.

An analysis of the compositions showed that almost all students in their work use at least one pictorial means, phraseological units, a word in a figurative meaning, a proverb, a hadith sayings of the prophet), cite several lines of poetry at the beginning or end of a written work.
In the 2015-2016 academic year, in the 9th grade of some schools, a card-type test was organized. These cards contained assignments in separate versions for each row in the class based on a literary text, one or two hemistiches. It was expected from the students: they should read the text verse) and determine the required linguistic phenomenon - an artistic means of expression a kind of poetic art), name it and explain it. In many cases, the students did not define and did not explain the word, word form, which is a means of representation, in some cases they limited themselves only to the name of the term. In some cases, they were unable to distinguish an artistic means of expression from a type of poetic art.

In the 9th grade of some schools, a test control was carried out aimed at determining what schoolchildren's knowledge of artistic expressive means and types of poetic art was, whether they were able to distinguish between them. In one test, it was required to indicate a row in which only artistic expressive means were listed, in the second, the types of poetic art. Control work covered 227 pupils. Only 121 students found the correct answer for the first test task, and 55 students for the second. The reason for this situation can be considered the fact that in literature lessons, classification information is not studied in a special way.

In order to streamline the studied knowledge, to reflect in them that the artistic means differ from the types of poetic art, from "qofia" and "radif" in versification, introduce classification information into textbooks; outlined a number of proposals for changes in the content of training, studied in the literature. These proposals are displayed in the following table 1:

Table No. 1. Content of teaching literary concepts based on integration with topics taught in the native language 


\begin{tabular}{|c|c|c|c|c|}
\hline$\frac{\tilde{z}}{\tilde{U}}$ & $\begin{array}{l}\text { Linguistic phenomena } \\
\text { studied and repeated } \\
\text { in high school in the } \\
\text { native language }\end{array}$ & $\begin{array}{l}\text { Linguistic } \\
\text { phenomena, } \\
\text { familiarized with } \\
\text { the native } \\
\text { language } \\
\text { practically }\end{array}$ & $\begin{array}{l}\text { Theoretical } \\
\text { concepts studied at } \\
\text { this time in } \\
\text { literature }\end{array}$ & $\begin{array}{l}\text { Theoretical concepts } \\
\text { for which it is } \\
\text { recommended to } \\
\text { change the stage of } \\
\text { training and introduce } \\
\text { new ones }\end{array}$ \\
\hline \multirow[t]{2}{*}{5} & $\begin{array}{l}\text { figurative meaning of } \\
\text { a word }\end{array}$ & $\begin{array}{l}\text { comparison } \\
\text { forms: -dek, -day } \\
\text { as, like)) }\end{array}$ & & $\begin{array}{l}\text { Comparison of } \\
\text { hyphenation } \\
\text { impersonation } \\
\text { hyperbole }\end{array}$ \\
\hline & figurative expressions & & & paraphrase \\
\hline \multirow[t]{2}{*}{6} & $\begin{array}{l}\text { stem and endings } \\
\text { same root words) }\end{array}$ & & & $\begin{array}{l}\text { istiqoq application of } \\
\text { words consisting of one } \\
\text { root) }\end{array}$ \\
\hline & $\begin{array}{l}\text { vowels and } \\
\text { consonants }\end{array}$ & $\begin{array}{l}\text { repetition of } \\
\text { identical } \\
\text { consonants }\end{array}$ & & alliteration \\
\hline \multirow[t]{3}{*}{7} & homonyms & & & $\begin{array}{l}\text { tajnis homonym - in } \\
\text { poetry) }\end{array}$ \\
\hline & single-chained words & & $\begin{array}{l}\text { tanosub application } \\
\text { of single-nested } \\
\text { words in poetry }\end{array}$ & \\
\hline & postposition & types of texts & $\begin{array}{l}\text { tashbih comparison } \\
\text { in poetry) }\end{array}$ & \\
\hline \multirow[t]{4}{*}{8} & $\begin{array}{l}\text { figurative meaning of } \\
\text { a word }\end{array}$ & & $\begin{array}{l}\text { Ko'chirish } \\
\text { allegory, symbol, } \\
\text { metaphor) }\end{array}$ & $\begin{array}{l}\text { classification } \\
\text { information }\end{array}$ \\
\hline & $\begin{array}{l}\text { figurative meaning of } \\
\text { a word }\end{array}$ & & artistic image & $\begin{array}{l}\text { tazod antonyms - in } \\
\text { poetry) }\end{array}$ \\
\hline & homonyms & & $\begin{array}{l}\text { tajnis pun - in } \\
\text { poetry), }\end{array}$ & epithet \\
\hline & antonyms & & $\begin{array}{l}\text { irsoli masal the use } \\
\text { of proverbs in } \\
\text { poetry) }\end{array}$ & exclamation in poetry) \\
\hline 9 & definition & $\begin{array}{l}\text { reuse of words } \\
\text { and sentences }\end{array}$ & $\begin{array}{l}\text { Theoretical } \\
\text { concepts studied at } \\
\text { this time in } \\
\text { literature }\end{array}$ & $\begin{array}{l}\text { syntactic figures; } \\
\text { gradation }\end{array}$ \\
\hline
\end{tabular}

In today's time, when reading and studying classical works, in particular, reading Alisher Navoi has become a necessity, the study of knowledge about the classification of artistic expressive means and types of poetic art acquires special significance. 
Linguo-methodological foundations of the integrated study of the native language with literature through literary texts.

The content of the study of the linguistic features of a literary text, using on the basis of the integration of theoretical concepts and information, familiarized with literature lessons, should form a holistic mechanism. This mechanism, first of all, should be provided with a sequence of types of work serving training, selected in accordance with the tasks of education, knowledge, and the transformation of skills into skills.

The process of forming knowledge, skills and abilities is organized by the types of work performed in a certain sequence: the study of the linguistic features of a literary text begins with the definition of the goal, in the process of finding, naming, explaining, creating a text in an artistic style, the sequential use of previously held knowledge, skills and skills.

In the drawing, presented in the form of a module, the types of work on the creation of a text in an artistic style are carried out after studying artistic visual means and types of poetic art starting from the 8th grade). However, with the classy introduction of the first five types of work, the presence of some distinctive aspects is ensured. These differences are manifested in the selection of a literary text, which contains an artistic visual medium or a type of poetic art, according to the principle from simple to complex, in the prescribed principle from easy to difficult in terms of expression of these means. For example, working on a comparison in grade 5, the teacher at first uses texts where there are words formatted with affixes -dek, -day as, like), syntactic constructions expressing the meaning of comparison. In the next stages, the teacher turns to passages with words that are formed in more complex forms in expression.

The work covers issues related to creative thinking. And also in it separate pages are allocated to the problem of the formation of knowledge, skills and abilities in the content of studying the peculiarities of the language of a literary text.

Simultaneous one after another) study of related knowledge in two academic subjects, while proceeding from the level of knowledge of students, encourages a deep understanding of them. In the work of Abu Reikhan Beruni "Monuments left over from ancient peoples" about the meaning of the time-based transition from one subject to another, it is said: "When a student moves from one subject to another, it seems to him that he is walking in different gardens. Not having time to see one thing, another begins and this person, as they say: "There is a kind of pleasure in every thing," will be interested in seeing and want to see them. One and the same thing tires, becomes a heavy burden on the memory. " This approach to the study of literary texts serves to the emergence of the integration of language and literature; literature lessons serve as a practical laboratory in the development of linguistic and communicative competencies in students.

This chapter draws attention to one of the problems of studying the linguistic features of a literary text - the issues of expressive reading of it. First, in pursuit of the goal of using the artistic and aesthetic thinking of students, they are given the task to expressively read a passage taken from the work. Only after such an educational event, attention to its linguistic features appears. There is a kind of psychological basis for such a beginning. According to psychology sources, artistic perception in native language lessons is different from artistic perception that occurs during expressive reading in literature lessons.

Speaking about the concept of the field of perception, the scientist psychologist $\mathrm{O} . \mathrm{K}$. Tikhomirov cites the following opinions of Gestalt psychologists: “... according to Gestalt psychologists, from the very beginning the field of perception that is, what we perceive at the moment) is structured: there is something in it that comes to the fore it is called a figure) and something that is 
in the background ... form a figure at the moment, and everything else ...) forms the background. The relationship between the figure and the background is mobile, not fixed, and at every single moment in the field of perception, there is a division into figure and background. " In this case, it will be correct to assume that when a student is looking for a linguistic phenomenon, perception contemplation) will primarily be directed to this linguistic phenomenon, and the artistic features of the literary material will be perceived in the background. When the attention of students, based on assignments, is directed to the literary material, to its linguistic features, these materials become a figure.

The dissertation comprehensively interprets such types of work as to find, name an artistic visual medium or a type of poetic art, determine what this artistic visual medium is for in the text, explain, analyze, including conduct a comprehensive analysis.

After, through a survey, he finds out what artistic figurative means and types of poetic art students know, the teacher instructs them to read the text to themselves again, find and name the artistic figurative means or type of poetic art.This type of work serves to consolidate and repeat information. learned about these funds. As the next type of work, the student is given the task to explain this means of expression. In this way, students acquire primary knowledge and skills in certain artistic visual means and types of poetic art. Finally, we can proceed to a comprehensive analysis of the linguistic features of a literary text. By this time, the students are already beginning to form the corresponding skills.

Experiments have shown that students have little difficulty in defining impersonation and hyperbole. However, they face difficulties in identifying the epithets that create imagery. In this regard, it is necessary to pay great attention to the exercises associated with the definition of epithets from the text.
Undoubtedly, if the teacher will often direct the attention of students to the skill of a writer or poet in the use of words and word forms in a literary text, these classes will help them to form positive habits and corresponding skills.

Questions and tasks on the definition and explanation of artistic visual means available in the text, create a new view of young people in relation to linguistic phenomena, direct thinking to the secrets of creativity; arouse great interest among students, teach them how to think with artistic visual means on the basis of life events, how to create images.

In the dissertation, based on the opinions of scientific psychologists and methodologists, interpretations of the concept of "owner of creative thinking", "owner of creative speech", the tasks of educating a creative and independently thinking personality are outlined.

The work recommends the implementation of a number of types of effective work on the development of oral and written speech of students, their speech culture.

In the course of the research, it was seen how a student studying the linguistic features of a literary text, creating his own speech product, doing these works in an elementary degree, editing the written creative written work, improves his creative thinking.

It is considered an important task of today, not limited to acquainting students with the rich possibilities of the language contained in the literary text, to encourage them to artistic creativity in the lessons of their native language, in a word, to develop their creative thinking.

Such types of work as the selection of words, the creation of images, the presentation of events, approaching the artistic style, serve as a factor that encourages students to be creative, and this ensures a further increase in the effectiveness of lessons in the native language. 


\section{Experimental Results}

In the 2015-2016 academic year, before the start of experimental lessons in 9 classes, in which these lessons are intended, in order to ascertain the knowledge, skills and abilities of students in finding from a literary text, artistic visual aids and types of poetic art, naming and explaining them, test papers.
After the lessons, on the basis of experimental materials, a mathematical calculation of the results of control works was carried out in order to compare the qualitative changes before and after the experiment. The results of mathematical analysis are reflected first for each school and class, then in a summary table, which summarizes the number of classes and students Table 2).

Table 2. Performance indicators for determining the degree of effectiveness of the results of tests carried out before and after the experiment on artistic visual aids and types of poetic art

\begin{tabular}{|c|c|c|c|c|c|c|c|}
\hline \multirow{2}{*}{$\begin{array}{l}\text { Test time: } \\
\text { before or } \\
\text { after }\end{array}$} & \multirow{2}{*}{$\begin{array}{l}\text { The total } \\
\text { number of } \\
\text { students } \\
\text { who } \\
\text { completed a } \\
\text { particular } \\
\text { type of task }\end{array}$} & \multicolumn{2}{|c|}{$\begin{array}{l}\text { Linguistic } \\
\text { phenomenon }\end{array}$} & \multicolumn{2}{|c|}{$\begin{array}{l}\text { Linguistic } \\
\text { phenomenon }\end{array}$} & \multicolumn{2}{|c|}{ Linguistic phenomenon } \\
\hline & & found & $\begin{array}{c}\text { not found or } \\
\text { identified } \\
\text { incorrectly }\end{array}$ & called & $\begin{array}{l}\text { not } \\
\text { called or } \\
\text { incorrect } \\
\text { ly called }\end{array}$ & $\begin{array}{l}\text { explain } \\
\text { ed }\end{array}$ & $\begin{array}{l}\text { did not } \\
\text { explain or } \\
\text { incorrectly } \\
\text { explained }\end{array}$ \\
\hline before & 218 & 39 & 209 & 70 & 148 & 24 & 214 \\
\hline after & 237 & 187 & 50 & 221 & 16 & 47 & 190 \\
\hline
\end{tabular}

By combining the indicators of found, named and explained linguistic phenomena; not found, not named and not explained or incorrectly found, named and explained linguistic phenomena

Table 3. General statistical analysis of the results obtained on the definition, naming and explanation of artistic means of expression and types of poetic art

\begin{tabular}{|l|c|c|c|}
\hline Test time: & The total \\
experiment & $\begin{array}{c}\text { number of } \\
\text { students who } \\
\text { completed } \\
\text { the type of } \\
\text { task }\end{array}$ & $\begin{array}{c}\text { Language phenomenon by type of task } \\
\text { the foumber of students } \\
\text { and explained the }\end{array}$ & $\begin{array}{c}\text { the number of students who did not } \\
\text { finguistic phenomenon } \\
\text { incorrectly, named and explained the } \\
\text { incorrect language phenomenon }\end{array}$ \\
\hline before & $218 \times 3$ & 133 & 521 \\
\hline after & $237 \times 3$ & 455 & 256 \\
\hline
\end{tabular}

In the paragraph devoted to the results of statistical analysis, the indicators of the above table were statistically analyzed. in separate generalized columns, 9 columns were brought into 2 columns and reflected in the following table. See table 3). 
Based on the results reflected in the above table, in an experiment conducted to determine the effectiveness of the results obtained in finding, naming and explaining artistic visual aids and types of poetic art, student performance before and after the experiment was analyzed using the StudentFisher mathematical-statistical method and Pearson $\chi 2$. The experiment involved a total of 1165 students. Of these, 654 participated before the experiment, and 711 after.

The brief essence of the problem is as follows: given two main sets. The first of which reflects the average scores after the experiment, the second - the average student scores before the experiment. We will assume that the estimates have a normal distribution. This assumption is appropriate, since the conditions for approximating the normal distribution are simple and they are satisfied.

On the basis of table 1, we select hypothesis $\mathrm{H}_{1}$ as an indicator of the effectiveness of students' progress before and after the experiment, and the opposite hypothesis $\mathrm{H}_{0}$ and reflect all this in the table.

Table 4. The effectiveness of the formation of the degree of indicators of academic performance before and after the experiment

\begin{tabular}{|c|c|c|l|}
\hline \multirow{2}{*}{ № } & Groups & \multicolumn{2}{|c|}{ Language phenomenon by type of task } \\
\cline { 3 - 4 } & $\begin{array}{l}\text { the number of students } \\
\text { who found, named and } \\
\text { explained the linguistic } \\
\text { phenomenon }\end{array}$ & $\begin{array}{l}\text { number of pupils, did not find, did } \\
\text { not name and did not explain or } \\
\text { found incorrectly, named and } \\
\text { explained the linguistic } \\
\text { phenomenon }\end{array}$ \\
\hline 1. & $\begin{array}{l}\text { Before experiment } \mathrm{n}_{1} \\
=654 \text { respondents }\end{array}$ & 196 & 458 \\
\hline 2. & $\begin{array}{l}\text { After experiment } \mathrm{n}_{2}= \\
711 \text { respondents }\end{array}$ & 384 & 327 \\
\hline
\end{tabular}

The diagram that fits these choices looks like this:

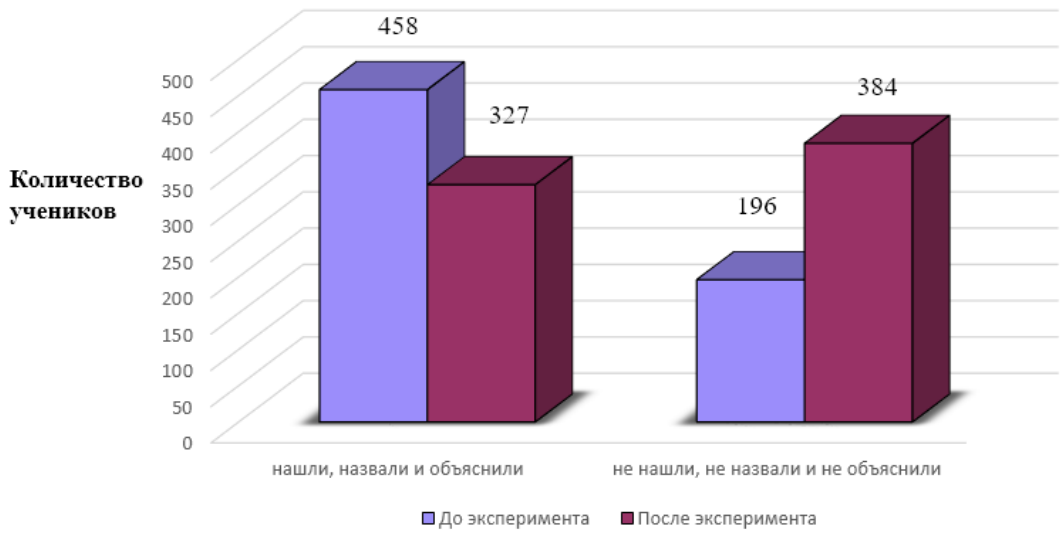

Figure 1. The effectiveness of the formation of the degree of indicators of academic performance before and after the experiment 
Consequently, it can be seen from the statistical analysis that the results of experimental work on teaching students to find, name and explain linguistic units are effective.

Conclusion

1. The increase in the number of literary texts in the textbooks "Native Language" for grades 5-9 has created the opportunity and the need to work on artistic visual aids and types of poetic art through these texts.

2. The expediency of the implementation of external and bilateral integration of the lessons of the native language with the lessons of literature through literary texts was substantiated, taking into account such basic approaches as communicativeness, focus on speech activity, ingenuity, consciousness and differentiation, such principles as paying attention to mastery in word usage, the content of teaching educational subjects, the native language and literature, has been brought into line with the point of view of artistic visual means and types of poetic art.

3. Recommendations were prepared for the redistribution of artistic visual aids and types of poetic art by classes and revision of classification materials based on the analyzes carried out in order to find out the availability of information about artistic visual aids and types of poetic art in the textbook and textbooks-readers "Literature" for grades 5-9, referring to them in the conditions of exercises, questions and assignments; interpretations and classifications set forth in sources on literary criticism, the possibilities of using them in the lessons of the native language are determined.

4. Control works carried out in the 9th grade showed that the knowledge, skills and abilities of students in finding, naming and explaining artistic visual aids and types of poetic art available in a literary text are not at the level of requirements, due to the fact that that they do not have sufficient classification information, they cannot distinguish between these means among themselves, as well as from the concepts of versification.

5. As it became known from the analysis of student's creative written works including essays), these works are written in a high spirit, as required by some topics, but in them artistic visual means are sometimes used correctly, and sometimes inappropriately, the students do not have enough mastery of using words. This circumstance makes it necessary to conduct educational activities in terms of convergence of written works of such content to artistry.

6. The educational components for the content of the study were determined based on the integration of the native language with literature through the literary text expressive reading, concept formation, finding, naming, explanation, complex analysis, text creation, control work), the sequence of types of work on these components was substantiated.

7. According to the doctrine of psychologists about the background and the figure, in order for an artistic text to become a figure, it is first necessary to perceive it artistically and read expressively, to feel its aesthetic impact, only after that it is advisable to direct the attention of students to its language features, with the help of which artistic value is created.

8. As a result of conducting in several lessons in the form of a separate stage in the order of educational activities recommended for work in the lessons of the native language on artistic visual aids and types of poetic art, mainly according to the scheme knowledge $\rightarrow$ skills of finding, naming, explanations, analysis $\rightarrow$ skills on them $\rightarrow$ finally, the formation of speech competence in relation to these linguistic phenomena is ensured by the predicted effectiveness mastering of knowledge, skills and abilities), the content of education, reflected in the plan, is improved, the students' interest in the language increases. 
9. The teaching methodology for finding, naming, explaining, analyzing the means that ensure artistry, creating an artistic style text in the lessons of the native language has been improved on the basis of the Bloom taxonomy levels knowledge, understanding, application, analysis, generalization).

10. The results obtained through the experimental lessons, the introduction of new ideas into practice, creative compositions created texts), which are reflected close to the artistic style in the form of presentation of events, choosing words, word forms, syntactic unity, creating images, indicate that students consistently develop a culture of speech.

\section{REFERENCES}

[1] Abdullaev Y. On the use of words. Collection "Issues of improving the teaching of Uzbek language and literature at school." - T .: O'zPFITI, 1982. - pp. 3-10.

[2] Abdullaev Y. On the visual-effective means of language. Collection "Problems of teaching the Uzbek language". - Toshkent, 1979. - pp. 3-10.

[3] Abdullaeva B.S. Methodological and didactic bases of interdisciplinary communication on the example of teaching mathematics in academic lyceums of socialhumanitarian direction): Dissertation of DCs. - Tashkent, 2006. - 264 p.

[4] Albetkova R.I. Methodical recommendations for the textbook "Russian Slovene. From words to words. Grade 5 ". 2nd ed., Stereotype. - M.: Bustard, 2001.$128 \mathrm{p}$.

[5] Albetkova R.I. Methodical recommendations for the textbook "Russian Slovene. From words to words. 6th grade". - 2nd ed., Stereotype. - M.: Bustard, 2001.$128 \mathrm{p}$.

[6] Albetkova R.I. Methodical recommendations for the textbook "Russian Slovene. From words to words. 7th grade". - 3rd ed., Stereotype. - M.: Bustard, 2002. $160 \mathrm{p}$.
[7] Doschinsky R.A. Work on the text in the lessons of the Russian language as a means of developing coherent speech of pupils of the 5th grade of a comprehensive school: Dissertation of Ph.D.: - M., 2005. - 207 p.

[8] Fazylova B. Consolidation of materials of the native language at the lessons of literature in IX-X grades of schools with the Uzbek language of instruction: Dissertation of Ph.D.: - Tashkent, 1983 .- 166 p.

[9] Ganshina Yu.V. Formation of the culture of speech of primary schoolchildren on literary material: Author's abstract. diss. ... Candidate of Pedagogical Sciences. Ryazan, 2007. -28 p. www.rspu.ryazan.ru

[10] Gulomov Y., Rasulov I., Rustamov H., Mirzaahmedov D. Methods of teaching Uzbek language. - T .: Teacher, 1975. - 280 p.

[11] Issues of interdisciplinary communication in the process of teaching the Uzbek language. Materials of the eighth meeting of the regular conference "Uzbek language". Tashkent: 2005. $-191 \mathrm{p}$.

[12] Loichenko A.B. Work with literary text as a means of fostering interest in Russian language lessons: Diss. ... Cand. ped. Sciences: Moscow, 1999. - 136 p.

[13] Mamon G.N. Work on pictorial and expressive means in the lessons of the Russian language in the process of research activities of students of specialized classes: Diss. ... Candidate of Pedagogical Sciences. - M., 2009. - 304 p.

[14] Markina E.E. Philological analysis of landscape poetic text at the integrated lesson of the Russian language and literature in the third-fifth grades of school as a means of speech development: Diss. ... Cand. ped. sciences. - Ulyanovsk, 1999. $166 \mathrm{p}$.

[15] Merkin G.S., Zybina T.M., Maksimchuk N.A., Ryabikova O.S. Development of speech. Expressive means of artistic speech: A guide for teachers. - 2nd ed., Rev. 
- M.: OOO "TID" Russian word - PC ", 2005. - 208 p.

[16] Pronina A. Linguistic analysis of the text as a means of developing students' speech: Dis .... cand. ped. Sciences: - SPb., 1998.- 146 p.

[17] Qobilova Z., Aliyeva G. Adabiyot darslarida fanlararo integratsiya. Til va adabiyot ta'limi. - 2015. - № 3. - pp. 2122.

[18] Semenova N.A. Methods of studying a literary text in the classroom for the course "Russian literature" in the X-XI grades of secondary school: Diss. ... Candidate of Pedagogical Sciences. - Samara, 2003. $208 \mathrm{p}$.

[19] Sokolova G.P. Lessons of the Russian language and literature: Study guide. - M.: Bustard, 2003.- 352 p. Master Class).

[20] Stukolkina G.P. Linguo-stylistic analysis of a literary text through a system of images) as a means of forming speech skills of primary schoolchildren: Diss. ... Candidate of Pedagogical Sciences. - Ryazan, 2007. $188 \mathrm{p}$.

[21] Tekuchev A.V. Methods of teaching Russian in secondary school. 3rd ed., Rev. - M.: Education, 1980.- 528 p.

[22] Yadgarov Q.M. Linguodidactic bases of teaching the language of literary work in academic lyceums: Dissertation of Ph.D.: Tashkent, 2007. - $150 \mathrm{p}$.

[23] Yoqubjonova O. Use of other subject materials in mother tongue lessons. - T. Teacher, 1988. - $75 \mathrm{p}$.

[24] Ziyodova T.U. Improving students' vocabulary in the process of mother tongue education: Dissertation of Ph.D.: - T., 1995. - $141 \mathrm{p}$.

[25] Zununov A., Aliev A. The study of literature in relation to other humanities. Teacher's Guide. - T .: Teacher, 1982. - 72 p. 